\title{
O efeito de smart money nos fundos de investimento: o caso português
}

The smart money effect in mutual funds: the Portuguese case

\begin{abstract}
In this article we analyze the investors' ability to select mutual funds, a phenomenon that is known as the smart money effect. The sample used concerns funds domiciled in Portugal for the 2003-2011 period. The empirical evidence suggests that investors had good skills when selecting mutual funds. When the market is in an upward (downward) phase, investors have the ability to select the funds in which to invest (disinvest) but they do not show the ability to choose the best funds to sell (buy). The intensity of the smart money effect seems also to depend on fund category and on the size of the funds.
\end{abstract}

\section{Keywords}

smart money effect; mutual funds; financial markets efficiency; Portugal.

JEL Codes G11; G15; G17; G20; G23.

\author{
Júlio Lobão \\ Universidade do Porto \\ Miguel Oliveira \\ Universidade do Porto
}

\section{Resumo}

O objetivo deste artigo é o de analisar a capacidade dos investidores em fundos de investimento para selecionar aqueles que apresentam rentabilidade mais elevada. Essa capacidade é denominada na literatura por efeito de smart money. A amostra utilizada diz respeito aos fundos sediados em Portugal, no periodo de 2003-2011. Os resultados indicam que, em geral, os investidores tiveram boa capacidade de seleção de fundos. Quando o mercado está em fase de subida (descida) de preços, os investidores têm a perícia de selecionar os fundos onde investir (desinvestir), mas não os fundos a liquidar (comprar). A intensidade do smart money parece ainda depender da categoria e da dimensão dos fundos transacionados.

\section{Palavras-chave}

smart money; fundos de investimento; eficiência dos mercados financeiros; Portugal.

Códigos JEL G11; G15; G17; G20; G23. 


\section{Introdução}

Neste artigo estudamos a capacidade dos investidores em fundos de investimento atuando no mercado português para selecionar os fundos que apresentam rentabilidade mais elevada. Essa capacidade é denominada na literatura por efeito de smart money.

Gruber (1996) e Zheng (1999) concluem que os investidores dos EUA têm capacidade de seleção de fundos. $O$ estudo do smart money é especialmente importante, uma vez que, como salienta Gruber (1996), constitui uma das explicações para o fato de os investidores preferirem fundos que adotam estratégias ativas de investimento, apesar das numerosas evidências de que seria mais vantajoso investir em fundos com estratégias passivas e menores custos (e.g., French, 2008; Fama; French, 2010).

Apesar de os estudos iniciais terem apontado a existência de smart money, artigos posteriores colocam em dúvida tal resultado. Por exemplo, Frazzini e Lamont (2008) defendem que os investidores seguem estratégias contrárias ao smart money, o que denominam de dumb money. A (in)capacidade dos investidores individuais para selecionar os melhores fundos é uma questão ainda em aberto na literatura (ver Tabela 1).

Para estudar o smart money no mercado dos fundos de investimento em Portugal, aplicamos três métodos de teste, distintos a dados com frequência mensal referentes ao período 2003-2011. O primeiro método utilizado consiste num teste à igualdade das rentabilidades médias de duas carteiras, uma das quais é constituída apenas por fundos de investimento que obtiveram subscrições líquidas positivas, e a outra composta dos fundos que tiveram saídas líquidas de capital. O segundo método de teste consiste na avaliação do desempenho de diferentes estratégias de transação de fundos com base na rentabilidade ajustada ao risco. O teste de causalidade de Granger foi o terceiro método de teste adotado para estudar o smart money. Atendendo à importância potencial do viés de sobrevivência (survivorship bias), foi adotado o método "follow the money" (Gruber, 1996; Keswani; Stolin, 2008) para responder ao problema.

Os resultados indicam que o smart money existiu no período em análise. O investidor poderia ter aproveitado a informação relativa às subscrições líquidas dos fundos para obter rentabilidades superiores às registradas pelo fundo médio. O desempenho dos investidores parece ser diferente consoante à fase do mercado em que atuam: quando o mercado está em fase de 
subida (descida) de preços, os investidores têm a capacidade de selecionar os fundos onde investir (desinvestir), mas não os fundos a liquidar (comprar).

O smart money é particularmente significativo nos fundos cujas carteiras são majoritariamente compostas de ações.

O comportamento dos investidores na seleção dos fundos parece ser diferenciado conforme a dimensão da carteira desses fundos. Os investidores em fundos de menor dimensão tendem a escolher aqueles que apresentaram melhor rentabilidade num passado recente (um a três meses), mas não exibem capacidade para identificar os fundos mais rentáveis. Já os investidores em fundos de maior dimensão parecem aplicar o seu dinheiro nos fundos que vão apresentar maior rentabilidade num horizonte temporal entre 6 e 12 meses.

São vários os contributos do presente artigo. Em primeiro lugar, os resultados apresentados proporcionam maior conhecimento acerca do fenômeno de smart money. Uma vez que o artigo recaia sobre um mercado em que a incidência do fenômeno é ainda pouco estudada, as conclusões são importantes para evitar o enviesamento de seleção decorrente de um excessivo foco nos mercados mais desenvolvidos. A importância do estudo do smart money em mercados diferentes é reforçada pelo fato de se saber que as conclusões obtidas em estudos sobre o tema para os EUA e o Reino Unido não são diretamente extrapoláveis para mercados com contextos institucionais e culturais diferentes. De fato, conforme mostram Ferreira et al. (2012), num estudo recente aos mercados de fundos de 28 países, a relação entre os fluxos de entrada e saída nos fundos e o seu desempenho varia de forma substancial de país para país, respondendo provavelmente a fatores locais, como a sofisticação dos investidores e os seus custos de participação.

Em segundo lugar, o presente estudo é um dos poucos que utilizam dados com frequência mensal; a maioria dos estudos sobre o tema recorre a dados com frequência mais baixa, sejam dados com frequência trimestral (e.g., Sapp; Tiwari, 2004; Bu; Lacey, 2008), sejam dados com frequência até mesmo anual (e.g., Marzuki; Worthington, 2011). A escolha da frequência dos dados pode parecer uma questão técnica com reduzida importância, mas, na verdade, pode ter implicações substanciais. Como refere Haq et al. (2011), a utilização de dados trimestrais dificulta a detecção da capacidade dos investidores na seleção dos fundos. Para além da óbvia vantagem de se ter maior número de observações e, por conseguinte, de se poder obter resultados mais fiáveis, a utilização de dados mensais para os fluxos de 
entrada e saída de aplicações nos fundos reduz a perda de precisão que advém da utilização de valores para esses fluxos referentes a períodos mais longos. A importância da escolha de dados com frequência mais elevada pode ser ilustrada com os resultados do estudo de Keswani e Stolin (2008): quando se utilizam dados trimestrais, os testes indicam que o smart money não existe; quando se utilizam os mesmos dados, mas com frequência mensal, o smart money revela-se estatisticamente significativo.

Em terceiro lugar, o estudo contribui para maior conhecimento acerca do comportamento dos investidores nas diferentes fases de evolução do mercado de ações (subida e descida de preços). Existem diversos estudos que sugerem que os investidores são mais sensíveis à informação em períodos negativos. Essa informação é mais rapidamente incorporada nos preços em períodos de sentimento negativo pelo que é mais difícil utilizá-la em estratégias capazes de obter rentabilidades supranormais. Por exemplo, Cooper et al. (2004) concluem que a informação histórica dos preços só permite obter rentabilidades supranormais positivas (estratégias de momentum) em alturas em que o mercado registra tendência de subida. E García (2013) mostra que os preços refletem muito mais rapidamente as notícias publicadas na secção financeira do jornal The New York Times durante períodos de recessão. No que diz respeito aos investidores em fundos de investimento, para além do presente artigo, existe apenas outro (Peng et al., 2011) em que a questão do comportamento dos investidores em fundos nas diversas fases do mercado é abordada. Os nossos resultados são consistentes com os argumentos apresentados por Peng et al. (2011). Os investidores, em fases pessimistas do mercado, mostram-se mais sensíveis a informações negativas, o que se traduz em melhoria das suas escolhas no momento de liquidação dos fundos.

Por último, no presente artigo adotam-se três metodologias de teste teste de igualdade das rentabilidades médias, teste de avaliação de desempenho e teste de causalidade de Granger - nunca antes aplicadas à amostra sob estudo. A utilização de diversos testes a esta amostra é crucial nos estudos a respeito da capacidade de seleção de fundos para assegurar maior robustez das conclusões obtidas. Aliás, essa é a prática recomendada por diversos autores que abordaram o tema (e.g., Keswani; Stolin, 2008).

O artigo está organizado em cinco secções. Na secção seguinte, revê-se a literatura sobre o smart money. Na terceira parte do artigo, apresentam-se os dados da amostra e os métodos a aplicar. A quarta parte é dedicada à 
apresentação e à discussão dos resultados dos testes empíricos. A secção das conclusões encerra o artigo, como o próprio nome sugere.

\section{Revisão da literatura}

O estudo acerca do smart money foi iniciado por Gruber (1996). Considerando uma subamostra de fundos de investimento em ações dos EUA, no período de 1985-1994, o autor encontrou evidências da existência de smart money.

Zheng (1999) expandiu a amostra de Gruber (1996) de forma a incluir todos os fundos de ação existentes entre 1970 e 1993. A conclusão principal é a de que os fundos que recebem subscrições líquidas positivas têm, subsequentemente, melhor desempenho (ajustado ao risco) do que os que têm subscrições líquidas negativas. Os investidores em fundos de menor dimensão parecem ter melhor capacidade de seleção do que os investidores nos fundos maiores.

Ao contrário de Gruber (1996) e Zheng (1999), Sapp e Tiwari (2004) defendem que o smart money resulta do fato de não se ter tido em conta o efeito de momentum. Para Sapp e Tiwari (2004), o smart money não se deve à capacidade dos investidores para identificar os melhores fundos. Segundo os autores, as ações que produzem maior momentum levam a maiores rentabilidades para um subconjunto dos fundos, e os investidores, sendo atraídos por essas rentabilidades, escolhem esses fundos. Ora, esses fundos, por deterem ações com maior momentum, são aqueles que acabarão por oferecer maior rentabilidade nos períodos posteriores.

Friedsen e Sapp (2007) concentram a sua atenção na capacidade dos investidores para escolher o momento de entrada e saída dos fundos de investimento (market timing). Com recurso a uma amostra de fundos dos EUA, os autores encontram evidências de dumb money entre 1991 e 2004: a falta de capacidade de escolha desses momentos traduz-se numa redução da riqueza dos investidores.

Em 2008 foram publicados quatro artigos relevantes na temática do smart money. Keswani e Stolin (2008), Bu e Lacey (2008), Frazzini e Lamont (2008) e Renneboog et al. (2008) chegam a conclusões contraditórias. Depois de reexaminarem os dados utilizados por Sapp e Tiwari (2004), Keswani e Stolin (2008) refutam as suas conclusões; mostram que o smart money existe e que não é resultado do momentum. Mais: Keswani e Stolin 
(2008) mostram que a ausência de smart money no estudo de Sapp e Tiwari (2004) decorre do fato de terem sido usados dados com frequência trimestral (com dados com frequência mensal, o smart money ter-se-ia revelado significativo) e de se ter dado um peso excessivo ao período anterior a 1991 (com uma amostra mais alargada, o smart money ressurge). Além de replicar o estudo de Sapp e Tiwari (2004) com os dados relativos aos EUA, Keswani e Stolin (2008) estudam o mercado de fundos do Reino Unido para o período 1991-2000, concluindo igualmente pela existência de um robusto smart money nesse país.

Bu e Lacey (2008) analisam o mercado de fundos dos EUA e, utilizando testes de causalidade de Granger, mostram que as evidências de smart money não são conclusivas; os sinais de smart money resultam, em significativa medida, do investimento em fundos com melhor desempenho no passado recente.

Frazzini e Lamont (2008), num estudo com dados referentes ao período de 1980-2003, nos EUA, apenas encontram o smart money no curto prazo (prazos de um trimestre), ao passo que o efeito que prevalece em horizontes de investimento mais longos é o inverso (dumb money). As decisões dos investidores em fundos conduzem à diminuição da sua riqueza no longo prazo.

Renneboog et al. (2008) examinam a indústria dos fundos de investimento socialmente responsáveis em nível mundial. Encontram sinais mistos da existência de smart money: embora não se mostrem capazes de identificar os fundos com melhor desempenho, os investidores naqueles fundos apresentam alguma capacidade para identificar os fundos com piores resultados.

Haq et al. (2011) inspiram-se em Keswani e Stolin (2008) para estudar os fundos do Reino Unido num período mais recente (2000-2010) e não encontram sinais significativos de smart money. Tal é atribuído à maior ênfase dos gestores de fundos em ganhos de curto prazo, o que dificulta a previsão da rentabilidade dos fundos e ao crescimento do número de fundos, com o consequente aumento nos custos de procura a suportar pelos investidores.

Mais recentemente, Yu (2012) documenta, para os EUA, forte smart money dos investidores em fundos de reduzida dimensão nos anos 19932008. Esse resultado decorre não apenas da sua capacidade para identificar os melhores fundos onde investir, mas também para identificar os melhores momentos de entrada e saída do mercado.

Apesar de mais escassos, existem alguns estudos acerca do smart money em mercados além dos EUA e do Reino Unido. Por exemplo, Gharghori et al. (2007) encontram sinais de smart money nos fundos de ações da Aus- 
trália, enquanto Gharghori et al. (2008) concluem que esse efeito não está presente na seleção dos fundos de pensões desse país. Vicente et al. (2011) utilizam uma amostra de fundos sediados na Espanha para mostrar que os pequenos investidores evidenciaram capacidade significativa de seleção durante o período 1997-2006. Em outro estudo, Andreu et al. (2010) consideram os mercados da Espanha (179 fundos) e da Alemanha (114 fundos) no período 1995-2005. Os autores confirmam a capacidade dos investidores espanhóis na seleção de fundos, mas não encontram smart money no mercado germânico.

No que diz respeito aos mercados asiáticos, Peng et al. (2011) mostram que o smart money foi significativo no mercado de Taiwan, entre 1998 e 2008, mas apenas nas fases de descida de preços do mercado de ações. Marzuki e Worthington (2011) analisam o mercado de fundos da Malásia. Entendida na sua globalidade, a capacidade de seleção dos investidores em fundos é fraca. Num estudo sobre os fundos de investimento na China, Feng et al. (2014) encontram sinais de dumb money. No entanto, os resultados são diferentes, consoante o tipo de investidores: os investidores institucionais exibem boa capacidade de seleção de fundos, ao contrário dos investidores individuais, que realizam (retiram) as suas aplicações financeiras nos fundos que apresentam pior (melhor) rentabilidade.

Existem, para o mercado brasileiro, alguns estudos sobre o tema. No caso de Costa e Eid Jr. (2006), os resultados apontam para a existência do smart money, mas a robustez dessa conclusão pode ser colocada em causa, dado que não foi controlado o viés de sobrevivência dos fundos. Varga (2011) considera o período 2005-2011 confirmando a existência de smart money, mas apenas para os investidores mais qualificados. Também aqui não foi controlado o viés de sobrevivência. Mais recentemente, Berggrun e Lizarzaburu (2015) estudam um período mais longo (2001-2012), corrigindo o viés de sobrevivência. Em geral, o smart money não se observou, embora os investidores em fundos menores tenham tido melhor capacidade de seleção.

Para o mercado português, existe apenas um estudo sobre o smart money. Alves e Mendes (2011) usam tabelas de contingência e análise multivariada para o período 1993-2009. Não encontram evidências significativas nem de smart money nem de dumb money: os fluxos financeiros num dado período são independentes do desempenho dos fundos no período seguinte.

Os resultados apresentados encontram-se resumidos na tabela seguinte: 
Tabela 1 Resumo dos resultados dos principais estudos empíricos sobre o smart money e o dumb money

\begin{tabular}{|c|c|c|c|c|}
\hline & Mercados & Há smart money & Não há smart money & Há dumb money \\
\hline \multirow{10}{*}{ 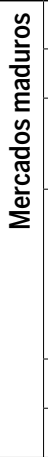 } & Alemanha & - & Andreu et al. (2010) & - \\
\hline & Austrália & Gharghori et al. (2007) & Gharghori et al. (2008) & - \\
\hline & Espanha & Vicente et al. (2011) & - & - \\
\hline & & Andreu et al. (2010) & & \\
\hline & EUA & Gruber (1996) & Sapp; Tiari (2004) & Friedsen; Sapp (2007) \\
\hline & & Zheng (1999) & Bu; Lacey (2008) & Frazzini; Lamont (2008) \\
\hline & & Keswani; Stolin (2008) & & \\
\hline & & Yu (2012) & & \\
\hline & Portugal & Presente estudo & Alves; Mendes (2011) & - \\
\hline & Reino Unido & Keswani; Stolin (2008) & Haq et al. (2011) & - \\
\hline \multirow{5}{*}{ 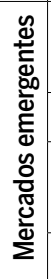 } & Brasil & Costa; Eid Jr. (2006) & Berggrun; Lizarzaburu & 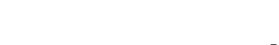 \\
\hline & & Varga (2011) & (2015) & - \\
\hline & China & - & - & Feng et al. (2014) \\
\hline & Malásia & & $\begin{array}{r}\text { Marzuki; Worthington } \\
\text { (2011) }\end{array}$ & \\
\hline & Taiwan & Peng et al. (2011) & - & - \\
\hline 号 & Multinacional & - & Renneboog et al. (2008) & - \\
\hline
\end{tabular}

Fonte: Elaboração própria.

Como se pode observar, não existe consenso na literatura acerca da capacidade dos investidores para identificar os fundos que apresentam melhor desempenho. Essa ausência de consenso justifica o interesse no estudo desta temática.

\section{Métodos e dados do estudo empírico}

\subsection{Métodos}

De forma a aumentar a robustez dos resultados, foram aplicados três métodos distintos de teste ao smart money.

O primeiro dos métodos consiste num teste à igualdade da rentabilidade média de duas carteiras com recurso ao teste t pareado. Uma das carteiras é constituída apenas por fundos de investimento que observaram 
subscrições líquidas de capital positivas no mês anterior, isto é, cujo valor das captações foi superior ao dos resgates (carteira positiva); e outra carteira é composta apenas de fundos que observaram saídas líquidas de capital no mês anterior (carteira negativa). Essas carteiras são atualizadas mensalmente para a totalidade dos fundos analisados. Se a rentabilidade da carteira positiva se mostrar significativamente superior à rentabilidade da carteira negativa, isso constitui evidência de smart money.

O segundo método consiste na avaliação do desempenho de diferentes estratégias de transação com base na rentabilidade ajustada ao risco. A existência de rentabilidade em excesso significativa entre as carteiras positivas e as carteiras negativas é indicação da existência de smart money. Uma vez que esse método exige a construção de carteiras com fundos homogêneos (ou seja, na mesma categoria) e em consonância com os contributos de vários autores (e.g., Gruber, 1996; Keswani; Stolin, 2008), consideraram-se apenas os fundos pertencentes à categoria dos "fundos de ações nacionais", de acordo com os critérios da Associação Portuguesa dos Fundos de Investimento, Pensões e Patrimônios (APFIPP). Para efetuar a comparação de rentabilidades, procedeu-se então à afetação desses fundos em diferentes carteiras, em cada um dos meses que compõem a amostra:

Carteira 1, designada por "Carteira normal": carteira constituída pela totalidade dos fundos, com igual ponderação;

Carteira 2, designada por "Carteira >0": carteira constituída por fundos que observaram subscrições líquidas de capital positivas durante o mês anterior, com igual ponderação;

Carteira 3, designada por "Carteira < 0": carteira constituída por fundos que observaram subscrições líquidas de capital negativas durante o mês anterior, com igual ponderação;

Carteira 4, designada por "Carteira $>0$ (ponderada)": semelhante à carteira 2 , mas com a rentabilidade ponderada pelas subscrições líquidas registradas no mês anterior;

Carteira 5, designada por "Carteira $<0$ (ponderada)": semelhante à carteira 3 , mas com a rentabilidade ponderada pelas subscrições líquidas registradas no mês anterior;

Carteira 6, designada por "Carteira $>0$ (normalizada)": semelhante à carteira 4, mas com as subscrições líquidas normalizadas, ou seja, o valor das subscrições considerado é a proporção entre a subscrição líquida veri- 
ficada no mês anterior e o volume de ativos sob gestão do fundo no mês anterior a esse;

Carteira 7, designada por "Carteira $<0$ (normalizada)": semelhante à carteira 5, mas com as subscrições líquidas normalizadas, ou seja, o valor das subscrições considerado é a proporção entre a subscrição líquida verificada no mês anterior e o volume de ativos sob gestão do fundo no mês anterior a esse.

O teste de causalidade de Granger é o terceiro método adotado para estudar o smart money. Uma vez que os métodos anteriores apenas averiguam se é possível a obtenção de rentabilidades em excesso a partir de uma estratégia de transação, não identificando se as subscrições líquidas possuem algum tipo de relação causal com as rentabilidades, o teste de causalidade de Granger é um complemento útil, já que permite isolar as relações entre diferentes variáveis. Assim, se as rentabilidades anteriores ao período $t$ tiverem precedência estatística em relação às subscrições líquidas ocorridas em $t$, tal indicia que maiores rentabilidades passadas atraem um maior volume de subscrições líquidas, o que é consistente com uma estratégia de momentum por parte dos investidores; por outro lado, se as subscrições líquidas ocorridas no período $t$ causarem estatisticamente as rentabilidades obtidas no período subsequente, tal é consistente com o smart money. Pelas razões aduzidas, também neste caso considerar-se-ão apenas a categoria dos "fundos de ações nacionais", segundo a APFIPP.

\subsection{Dados}

Neste artigo são consideradas duas amostras. A primeira engloba 322 fundos que operaram no mercado português, entre janeiro de 2003 e dezembro de 2011. O teste de igualdade das rentabilidades médias das carteiras incidirá sobre tal amostra e também sobre 28 subamostras construídas com base nessa amostra mais completa em função da categorização de fundos da APFIPP. Já o modelo unifatorial e o teste de causalidade de Granger serão aplicados a uma subamostra referente ao mesmo período temporal, mas constituída apenas por 7 fundos de ações nacionais.

Os dados utilizados são de dois tipos: as subscrições líquidas mensais dos fundos e as suas cotações diárias. Os primeiros foram obtidos na AP- 
FIPP. As cotações diárias dos fundos foram granjeadas na Comissão de Mercado de Valores Mobiliários (CMVM).

Todos os dados referentes às subscrições líquidas foram normalizados, isto é, as entradas líquidas de capital foram divididas pelos volumes sob gestão do ano anterior. Desta forma, diminuem-se os enviesamentos provocados por entradas de capital dos fundos com maiores volumes sob gestão, ao mesmo tempo em que se confere maior relevância às entradas de capital dos fundos de menor dimensão que, de outra forma, seriam subvalorizadas.

Os critérios de seleção de fundos foram os sugeridos por Keswani e Stolin (2008): excluíram-se os fundos com menos de 10 meses de dados de subscrições líquidas (havia 93 fundos nessa situação) e os fundos que apresentaram observações relativas a subscrições líquidas mensais que distem mais do que cinco desvios padrão em face da média das subscrições de todos os fundos nesse período (havia apenas dois fundos nessa situação). A amostra, assim construída, inclui 322 fundos.

Para minimizar o problema do enviesamento de sobrevivência, recorreu-se ao método "follow the money" utilizado na generalidade dos estudos na área (e.g., Gruber, 1996; Keswani; Stolin, 2008): sempre que ocorre uma fusão de fundos, presume-se que os montantes foram transferidos para o fundo que continuou a existir após a operação. Os dados relativos às fusões de fundos foram obtidos na APFIPP.

Não foram considerados na amostra inicial nem os fundos fechados (em razão dos limites impostos às subscrições após o início de atividade) nem o único fundo de ações indexado existente no mercado português (porque se trata de um fundo de gestão passiva).

$\mathrm{Na}$ Tabela 2, a seguir, apresentam-se algumas estatísticas relativas à amostra global e à subamostra de fundos de ações nacionais.

Como se pode constatar, podem ser distinguidas duas fases no que diz respeito às subscrições líquidas dos fundos. Durante os primeiros três anos da amostra (2003-2005), as subscrições líquidas foram bastante positivas, tendo atingido um total de mais de 4.228 milhões de euros. No entanto, a partir de 2006, a tendência inverteu-se: com exceção de 2009, todos os anos registraram um saldo negativo nas subscrições. Particularmente impressivo é o valor observado em 2008, ano em que a crise financeira internacional começou a atingir dimensões mais notórias, em que se registraram liquidações líquidas superiores a 8.966 milhões de euros, mais 


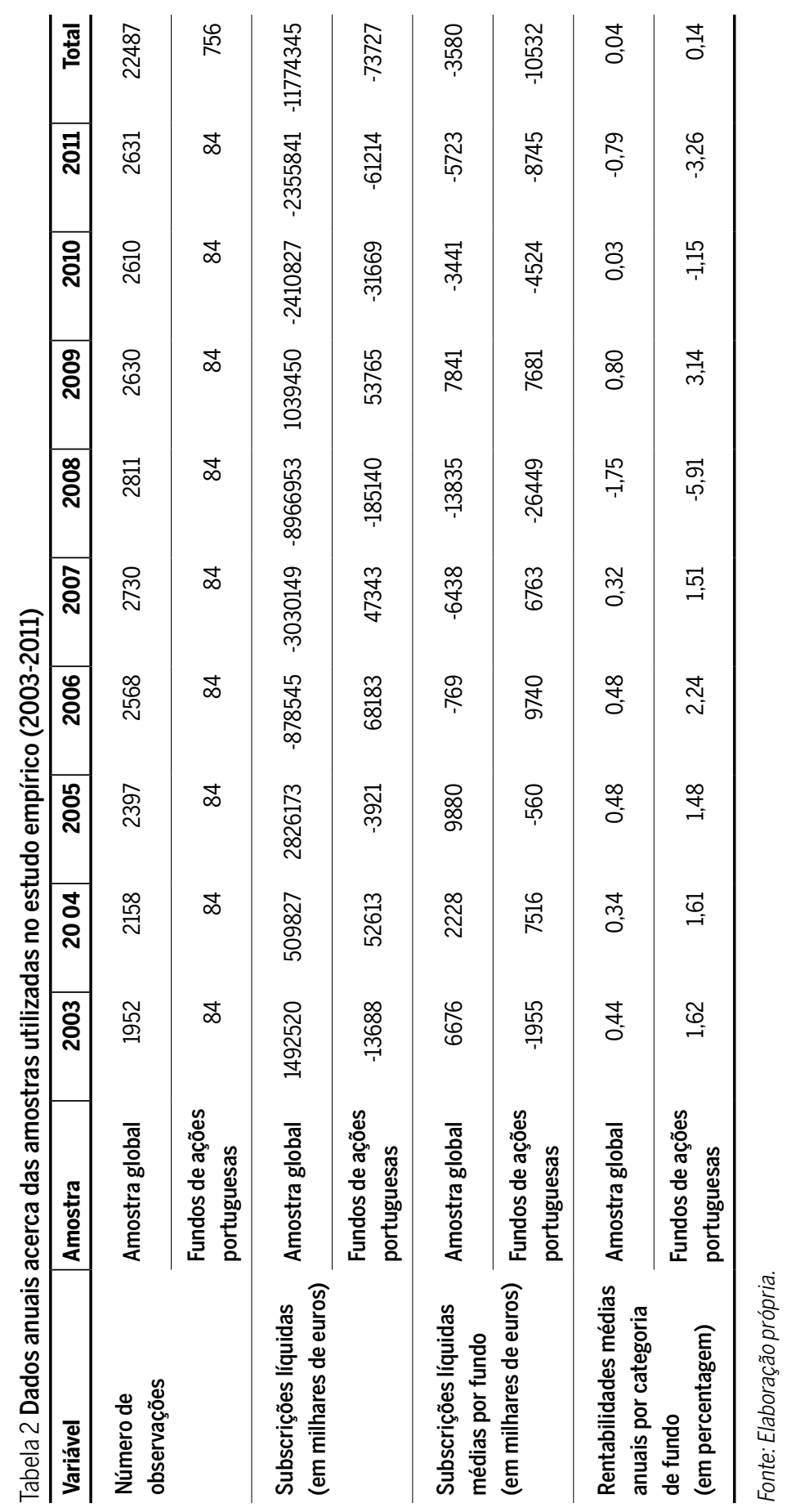


do dobro do que a entrada de recursos verificada nos três primeiros anos da amostra. No total do período, os fundos da amostra perderam mais de 11.774 milhões de euros sob gestão.

No caso dos fundos de ações portuguesas, a tendência de evolução ao longo do período não é tão clara, mas, ainda assim, no total do período da amostra, as perdas por via das subscrições e resgates somam mais de 73 milhões de euros.

Os dados revelam que a rentabilidade média anual do fundo típico sediado em Portugal se cifrou em $0,04 \%$ durante o período analisado; para os fundos de ações portuguesas, o valor foi de $0,14 \%$.

A comparação entre as rentabilidades médias dos fundos geridos de forma ativa e as rentabilidades do único fundo de índice a operar em Portugal pode ser observada na Tabela 3, a seguir.

Tabela 3 Rentabilidades médias dos fundos de ações portuguesas e do fundo de índice BBVA PPA - Índice PSI20, em percentagem (2003-2011)

\begin{tabular}{lc|c|c|c|c|c|c|c|c|c}
\hline Amostra & $\mathbf{2 0 0 3}$ & $\mathbf{2 0 0 4}$ & $\mathbf{2 0 0 5}$ & $\mathbf{2 0 0 6}$ & $\mathbf{2 0 0 7}$ & $\mathbf{2 0 0 8}$ & $\mathbf{2 0 0 9}$ & $\mathbf{2 0 1 0}$ & $\mathbf{2 0 1 1}$ & Total \\
\hline $\begin{array}{l}\text { Fundo BBVA PPA } \\
- \text { Índice PSI20 }\end{array}$ & 1,14 & 1,34 & 1,07 & 2,48 & 1,70 & $-5,64$ & 2,84 & $-0,10$ & $-2,68$ & 0,24 \\
\hline $\begin{array}{l}\text { Fundos de ações } \\
\text { portuguesas }\end{array}$ & 1,62 & 1,61 & 1,48 & 2,24 & 1,51 & $-5,91$ & 3,14 & $-1,15$ & $-3,26$ & 0,14 \\
\hline
\end{tabular}

Fonte: Elaboração própria.

O fundo de índice registrou rentabilidade média anual de $0,24 \%$ contra os $0,14 \%$ dos fundos de ações portuguesas. Esse resultado ilustra o enigma identificado por Gruber (1996), que questiona a utilidade dos fundos de gestão ativa do ponto de vista do investidor individual. De fato, os dados indicam que a melhor escolha do ponto de vista do investidor seria investir em fundos de gestão passiva que tendem a ter comissões substancialmente inferiores.

\section{Resultados do estudo empírico}

A seguir, apresentam-se os resultados da aplicação dos três testes empíricos considerados: o teste de igualdade das rentabilidades médias (secção 4.1), o modelo unifatorial (4.2) e o teste de causalidade de Granger (4.3). 


\subsection{Teste de igualdade das rentabilidades médias}

O teste de igualdade das rentabilidades médias foi aplicado à amostra global, composta de 322 fundos. Os resultados apresentam-se na Tabela 4, a seguir.

Tabela 4 Teste de igualdade das rentabilidades médias para a amostra global

\begin{tabular}{l|r|r|r|r}
\hline & $\begin{array}{r}\text { Rentabilidade } \\
\text { média anual } \\
\text { (em percenta- }\end{array}$ & Desvio padrão & \multicolumn{2}{|r}{$\begin{array}{r}\text { Teste de Igualdade de } \\
\text { Rentabilidades Médias }\end{array}$} \\
\hline gem) & & & $\begin{array}{r}\text { Teste t de } \\
\text { student }\end{array}$ & p-value \\
\hline Carteira $>0$ & 3,21 & 0,0825 & - & - \\
\hline Carteira $<0$ & $-3,04$ & 0,0906 & - & - \\
\hline Carteira $>0$ - Carteira $<0$ & 6,25 & 0,1187 & 9,4455 & 0,0001 \\
\hline
\end{tabular}

Fonte: Elaboração própria.

Com base nos 322 fundos da amostra, foram construídas duas carteiras: uma constituída apenas por fundos que observaram subscrições líquidas de capital positivas no mês anterior (carteira >0), e outra composta apenas de fundos com saídas líquidas de capital no mês anterior (carteira <0). A atualização das carteiras foi realizada mensalmente para cada um dos 108 meses da amostra, no período 2003-2011. Foi calculada a rentabilidade de ambas as carteiras, tendo em conta a rentabilidade mensal de cada fundo e presumindo que todos os fundos possuem o mesmo peso nas respectivas carteiras. Para testar a igualdade das rentabilidades médias anuais das duas carteiras, foi utilizado o método de teste t pareado (paired samples t-test). A hipótese nula é a de que as duas carteiras não são estatisticamente diferentes.

Os resultados sugerem que o smart money se verificou nos fundos de investimento a atuar em Portugal, no período 2003-2011. A diferença entre a rentabilidade média anual da carteira positiva $(3,21 \%)$ e a da carteira negativa $(-3,04 \%)$ revelou-se estatisticamente significativa a um nível de $1 \%$ de significância. Se fosse possível ao investidor comprar posições em todos os fundos que constituem a carteira positiva e simultaneamente vender os fundos de investimento da carteira negativa, tal permitiria obter rentabilidade anual média de 6,25\%.

A existência de uma diferença significativa na rentabilidade das duas carteiras constitui um desafio à hipótese de random walk, segundo a qual não seria possível detectar uma estratégia que permita obter os ativos com maior rentabilidade sem assumir um nível superior de risco. Ora, os resultados mostram que a carteira positiva, apesar de ter um risco inferior à carteira negativa de acordo com o desvio padrão, permite obter rentabilidade superior. 
É interessante analisar ainda se o potencial de ganho que decorre do smart money é mais ou menos acentuado consoante à categoria dos fundos em que se pretenda investir. Na Tabela 5, a seguir, apresentam-se os resultados dos testes à igualdade das rentabilidades médias desagregados por um conjunto selecionado de categorias de fundos.

Tabela 5 Teste de igualdade das rentabilidades médias para um conjunto selecionado de categorias de fundos

\begin{tabular}{|c|c|c|c|}
\hline & Categoria de fundos & $\begin{array}{r}\text { Rentabilidade média } \\
\text { anual da Carteira }>0 \\
- \text { Carteira }<0 \\
\text { (em percentagem) }\end{array}$ & p-value \\
\hline \multirow{2}{*}{$\begin{array}{l}\text { Fundos de } \\
\text { tesouraria } \\
\text { e mercado } \\
\text { monetário }\end{array}$} & F. Mercado Monetário Euro & 0,06 & 0,8080 \\
\hline & Fundos de Tesouraria Euro & 1,11 & 0,0001 \\
\hline \multirow{3}{*}{$\begin{array}{l}\text { Fundos com } \\
\text { obrigações }\end{array}$} & F. Mistos Predominantemente de Obrigações & $-5,37$ & 0,1100 \\
\hline & F. Obrigações Taxa Indexada Euro & 2,40 & 0,0753 \\
\hline & F. Obrigações Taxa Fixa Euro & 3,75 & 0,1500 \\
\hline \multirow{2}{*}{$\begin{array}{l}\text { Fundos } \\
\text { com ações }\end{array}$} & Fundos de Ações Portuguesas & 31,36 & 0,0001 \\
\hline & F. Ações da U.E., Suíça e Noruega & 15,85 & 0,0002 \\
\hline
\end{tabular}

Fonte: Elaboração própria.

Com base nos 322 fundos da amostra, foram construídas duas carteiras para cada uma das categorias de fundos definidas pela APFIPP: uma constituída apenas por fundos de investimento que observaram subscrições líquidas de capital positivas no mês anterior (carteira >0), e outra composta apenas de fundos que observaram saídas líquidas de capital no mês anterior (carteira <0). A atualização das carteiras foi realizada mensalmente para cada um dos 108 meses da amostra, no período 2003-2011. Foi calculada a diferença entre a rentabilidade da carteira $>0$ e a rentabilidade da carteira $<0$, tendo em conta a rentabilidade mensal de cada fundo e presumindo que todos os fundos possuem o mesmo peso nas respectivas carteiras. Para testar a igualdade das rentabilidades médias anuais das duas carteiras, foi utilizado o método de teste t pareado (paired samples t-test). A hipótese nula é a de que as duas carteiras não são estatisticamente diferentes.

A análise das sete categorias de fundos revela um panorama com grande diversidade de situações. O smart money mostrou-se estatisticamente significativo em várias categorias como os fundos de tesouraria euro, os fundos de ações portuguesas e os fundos de ações da U.E., Suíça e Noruega. Merece ser destacado o extraordinário valor de 31,36\% de rentabilidade média anual que se teria obtido com uma estratégia de smart money no 
caso dos fundos de ações portuguesas. Há situações em que o smart money não é estatisticamente significativo (como o caso dos fundos do mercado monetário euro) e situações em que as rentabilidades foram superiores na carteira de fundos em que os investidores desinvestiram (fundos mistos predominantemente de obrigações), embora neste caso o efeito não seja significativo a um nível de significância de $10 \%$.

Como interpretar resultados tão díspares? Os resultados sugerem capacidade muito diferenciada por parte dos investidores em cada uma das categorias de fundos para identificar os fundos que se vão revelar mais bem-sucedidos. Existem pelo menos duas justificações possíveis (não mutuamente exclusivas) para isso: a hipótese da segmentação dos mercados de fundos e a hipótese informacional. No primeiro caso, os resultados podem dever-se à segmentação do mercado dos fundos de investimento, com o nível de sofisticação dos investidores a variar em função das categorias de fundos. Segundo essa hipótese, os investidores que selecionam, por exemplo, fundos de ações portuguesas seriam mais sofisticados do que aqueles que escolhem fundos mistos compostos predominantemente por obrigações. Já na hipótese informacional, os resultados diversos segundo às categorias de fundos podem ficar a dever-se a diferentes níveis de acessibilidade da informação. De acordo com as características dos ativos em que investem os fundos pertencentes a uma dada categoria, é de supor que as informações capazes de guiar os investidores na escolha dos fundos que se vão revelar mais rentáveis tenham diferentes níveis de acessibilidade. Nesse caso, independentemente do nível de sofisticação do investidor, uma informação menos acessível pode dificultar a concretização com sucesso de estratégias de smart money. Estudos recentes como o de Del Guercio e Reuter (2014) sugerem que os investidores em fundos estão segmentados em clientelas com diferentes níveis de sofisticação e que isso se traduz na sua capacidade para obter rentabilidade superior à de uma estratégia passiva. Tais conclusões apontam para a primeira das explicações apresentadas.

\subsection{Avaliação de desempenho}

A avaliação de desempenho procura medir as diferenças de rentabilidade entre as carteiras positivas e as carteiras negativas de uma amostra consti- 
tuída por fundos de ações portuguesas e entre essas carteiras e o mercado. Para isso, recorre-se ao modelo unifatorial descrito na secção anterior.

Os resultados apresentam-se na Tabela 6 , a seguir.

Tabela 6 Desempenho das novas carteiras estimado através de um modelo unifatorial

\begin{tabular}{|c|c|c|c|c|}
\hline \multicolumn{5}{|c|}{ Painel A Desempenho das carteiras } \\
\hline Carteiras & $\begin{array}{r}\text { Rentabilidade } \\
\text { em excesso } \\
\text { mensal }\end{array}$ & Alfa & Rend. média & Desvio padrão \\
\hline \multirow[t]{2}{*}{ 1. Carteira normal } & $-0,0003$ & 0,0436 & 0,0002 & 0,0514 \\
\hline & & $(0,0000)$ & & \\
\hline \multirow[t]{2}{*}{ 2. Carteira $>0$} & 0,0139 & 0,0565 & 0,0143 & 0,0504 \\
\hline & $(0,0198)$ & $(0,0000)$ & & \\
\hline \multirow[t]{2}{*}{ 3. Carteira $<0$} & $-0,0021$ & 0,0335 & $-0,0017$ & 0,0492 \\
\hline & $(0,8263)$ & $(0,0000)$ & & \\
\hline \multirow{2}{*}{$\begin{array}{r}\text { 4. Carteira }>0 \\
\text { (ponderada) }\end{array}$} & 0,0049 & 0,013 & 0,0053 & 0,0497 \\
\hline & $(0,0035)$ & $(0,0065)$ & & \\
\hline \multirow{2}{*}{$\begin{array}{r}\text { 5. Carteira }<0 \\
\text { (ponderada) }\end{array}$} & $-0,0005$ & 0,0078 & $-0,0001$ & 0,0184 \\
\hline & $(0,1247)$ & $(0,0484)$ & & \\
\hline \multirow{2}{*}{$\begin{array}{l}\text { 6. Carteira >0 } \\
\text { (normalizada) }\end{array}$} & 0,0012 & 0,0018 & 0,0016 & 0,0242 \\
\hline & $(0,0347)$ & $(0,3194)$ & & \\
\hline \multirow{2}{*}{$\begin{array}{l}\text { 7. Carteira }<0 \\
\text { (normalizada) }\end{array}$} & $-0,0008$ & $-0,0001$ & $-0,0004$ & 0,0188 \\
\hline & $(0,0615)$ & $(0,4389)$ & & \\
\hline
\end{tabular}

Painel B Diferença no desempenho entre carteiras positivas e negativas

\begin{tabular}{lrr}
\hline & Rentabilidade em excesso & Alfa \\
\hline Carteira 2 - Carteira 3 & 0,016 & 0,023 \\
\cline { 2 - 3 } & & $(0,1242)$ \\
\hline Carteira 4 - Carteira 5 & 0,0054 & 0,0052 \\
\cline { 2 - 3 } & & $(0,2978)$ \\
\hline Carteira 6 - Carteira 7 & 0,002 & 0,0019 \\
\cline { 2 - 3 } & & $(0,0005)$ \\
\hline
\end{tabular}

Fonte: Elaboração própria.

Todos os meses, de janeiro de 2003 a dezembro de 2011, os fundos de investimento são distribuídos por carteiras positivas e por carteiras negativas com base no sinal da subscrição líquida verificada no mês anterior. A rentabilidade em excesso é obtida pela diferença entre $R_{p t}$ e $R_{m t}$, onde $R_{p t}$ é a rentabilidade da carteira ientre o mês $t$ - 1 e o mês $t$, e $R_{m t}$ é a rentabilidade do mercado de ações português, representada pela rentabilidade mensal do PSI20. O p-value em parênteses testa a diferença entre a rentabilidade de uma dada carteira e a rentabilidade de mercado. 0 valor de alfa é obtido pela regressão de um mo- 
delo unifatorial $R_{p t}-R_{f t}=\alpha_{p}+\beta_{p}\left(R_{m t}-R_{f t}\right)+\varepsilon_{p t}$, onde $R_{p t}-R_{f t}$ representa a rentabilidade em excesso da carteira de fundos p relativamente à taxa de juro sem risco no mês $t ; R_{m t}-R_{f t}$ representa o prêmio da carteira de mercado no momento $t$ dado pela diferença entre a taxa de rentabilidade de mercado no momento $t$ e a taxa de juro sem risco no ano $t$, em que foi utilizada a taxa de juro de uma obrigação de dívida pública alemã há 10 anos como referência. 0 p-value em parênteses testa se o alfa é significativamente diferente de zero. $0 \mathrm{p}$-value da diferença das carteiras testa a igualdade da rentabilidade entre uma dada carteira positiva e uma dada carteira negativa. As medidas de desempenho apresentadas referem-se a rentabilidades referidas ao período de um mês.

No painel A apresentam-se as rentabilidades em excesso mensais em relação ao mercado. A rentabilidade média mensal em excesso do fundo típico foi negativa durante todo o período da amostra, indicando que, em média, os gestores dos fundos de investimento não foram capazes de superar o mercado. Já no que diz respeito aos investidores em fundos, os valores obtidos mostram que parece existir alguma capacidade por parte desses agentes para obter rentabilidades superiores à carteira normal. As carteiras positivas 2, 4 e 6 apresentam rentabilidades em excesso positivas, enquanto as carteiras negativas 3, 5 e 7 mostram rentabilidades em excesso negativas. As rentabilidades em excesso das carteiras positivas são todas positivas e, portanto, superiores à rentabilidade da carteira normal. Já as rentabilidades em excesso das carteiras negativas são, em todos os casos, negativas e de valor inferior à rentabilidade da carteira normal, embora os resultados das carteiras 3 e 5 não sejam estatisticamente diferentes de zero a um nível de significância de $10 \%$.

As rentabilidades em excesso positivas (negativas) nas carteiras positivas (negativas) podem ser entendidas como as rentabilidades em excesso geradas pelos novos investimentos (desinvestimentos) nos fundos. Assim, verifica-se que a rentabilidade obtida nos novos fluxos ultrapassou a rentabilidade em excesso do fundo médio. Esse resultado suporta a hipótese de que investidores sofisticados podem obter melhor desempenho do que esse fundo médio. A rentabilidade em excesso da carteira negativa 7 é negativa e estatisticamente diferente de zero a um nível de significância de 10\%. Tal resultado sugere que essa carteira tem desempenho inferior à do mercado. Assim, e nessa medida, existe evidência de que os investidores retiram recursos dos fundos que subsequentemente apresentam desempenho inferior ao do mercado.

Relativamente aos alfas do modelo unifatorial, também podemos encontrar evidência do smart money. As carteiras positivas apresentam valores do alfa positivos e superiores aos dos alfas das respectivas carteiras negativas. Relativamente ao teste de significância individual, todos os alfas, à 
exceção dos alfas das carteiras 6 e 7 (normalizadas), rejeitam a hipótese nula de que os alfas não são estatisticamente diferentes de zero, com um nível de significância de 5\%.

No painel B constam as rentabilidades em excesso geradas através de estratégias em que se toma uma posição longa nas carteiras positivas e uma posição curta nas carteiras negativas. A diferença na rentabilidade das carteiras evidencia o smart money, com um nível de significância estatística de 1\%, para a terceira das estratégias analisadas (diferença entre as carteiras normalizadas). Apesar das rentabilidades e dos alfas médios se apresentarem positivos em todos os casos, apenas na estratégia referida os valores são estatisticamente diferentes de zero para níveis convencionais de significância estatística. Esses resultados corroboram parcialmente os obtidos no teste de diferença às rentabilidades médias dos fundos de ações portuguesas (ver seção 4.1).

Deve ser notado que todas as rentabilidades e alfas são mensais. Tal significa, a título de exemplo, que a rentabilidade em excesso anual média da carteira 4 é de cerca de 5,88\% (=0,49\%*12). Caso fosse possível realizar uma estratégia que aliasse posições longas na carteira 4 a posições curtas na carteira 5 , então a rentabilidade em excesso anual média ao longo do período em análise seria de 6,48\% (=0,54\%*12).

\subsubsection{Avaliação do desempenho em diferentes fases do mercado}

Analisamos ainda a existência de smart money em diferentes fases de mercado (fases de subida de preços vs. fases de descida de preços). Uma análise semelhante foi levada a cabo por Peng et al. (2011), tendo os autores concluído que o smart money se mostrou significativo apenas em fases de descida de preços. De forma a obter resultados comparáveis, adotamos o mesmo critério de classificação das fases de mercado: a fase de subida (descida) de preços é aquela em que a rentabilidade média do mercado nos 36 meses anteriores é positiva (negativa). No presente estudo, foi utilizada como referência da rentabilidade do mercado as cotações do índice PSI20, tendo-se encontrado apenas um ponto de inflexão, em setembro de 2008. Assim, temos dois subperíodos com tendências diferentes. $\bigcirc$ que compreende a fase de subida de preços prolonga-se desde o início da amostra (janeiro de 2003) até setembro de 2008 e o que abrange a descida de preços vai desde outubro de 2008 a dezembro de 2011. 
Os resultados respeitantes a cada uma das fases apresentam-se nas Tabelas 7 e 8 , a seguir.

Tabela 7 Desempenho das novas carteiras na fase de subida de preços

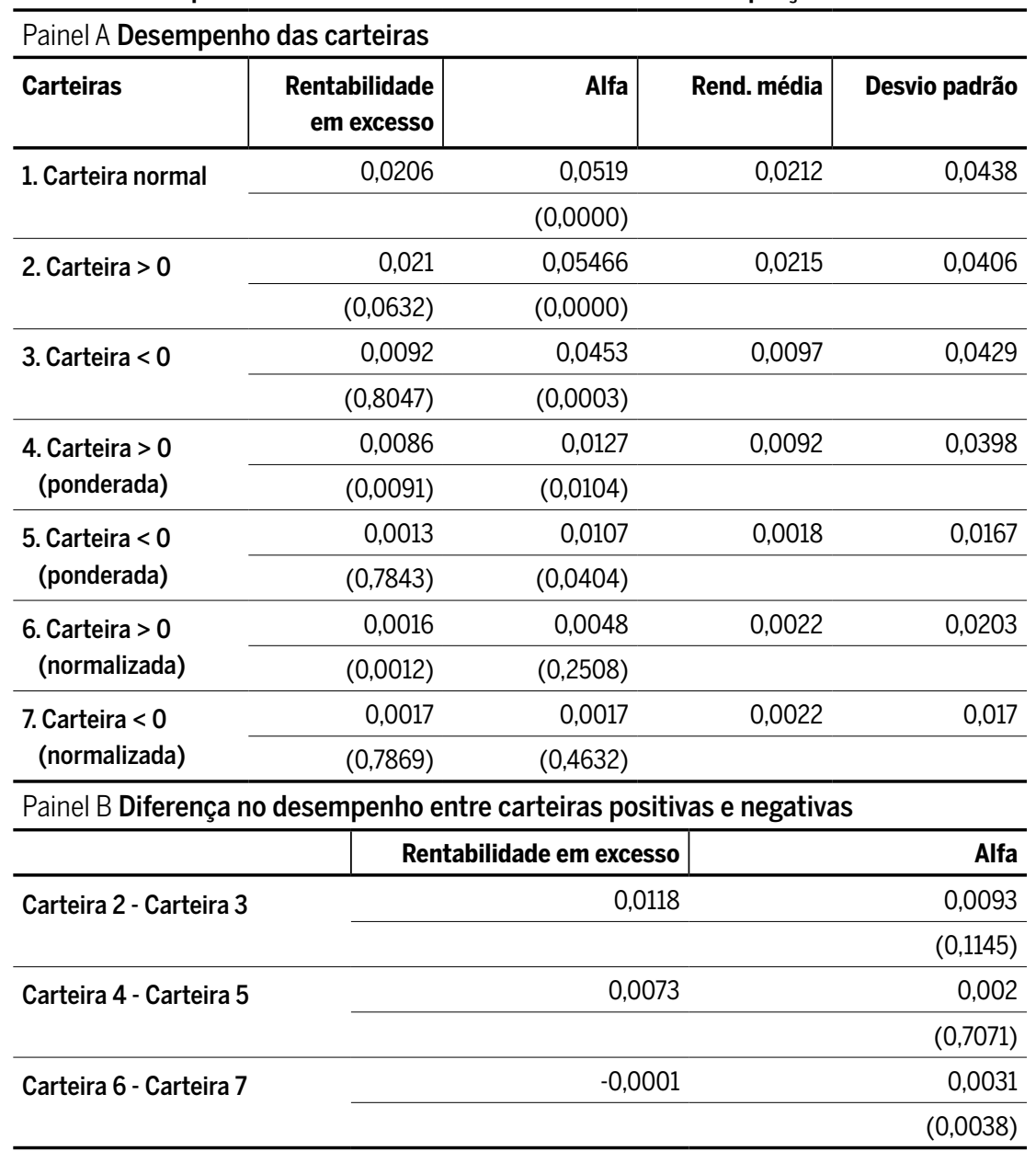

Fonte: Elaboração própria.

A fase de subida de preços foi definida como o período em que é positiva a média das rentabilidades do índice PSI20 nos 36 meses anteriores. Esse período vai de janeiro de 2003 a setembro de 2008. Todos os meses durante tal período, os fundos de investimento são distribuídos por carteiras positivas e por carteiras negativas com base no sinal da subscrição líquida verificada no mês anterior. A rentabilidade em excesso é obtida pela diferença entre $R_{p t}$ e $R_{m t}$, onde $R_{p t}$ é a rentabilidade da carteira $i$ entre o mês $t$ - 1 e o mês $t$, e $R_{m t}$ é a rentabilidade do mercado de ações português, representada pela rentabilidade mensal do PSI20. O p-value em parênteses testa a diferença entre a rentabilidade de uma dada carteira e a rentabilidade de mercado. 0 valor de alfa é obtido pela regressão de um modelo unifatorial 
$R_{p t}-R_{f t}=\alpha_{p}+\beta_{p}\left(R_{m t}-R_{f t}\right)+\varepsilon_{p t}$, onde $R_{p t}-R_{f t}$ representa a rentabilidade em excesso da carteira de fundos p relativamente à taxa de juro sem risco no mês $t ; R_{m t}-R_{f t}$ representa o prêmio da carteira de mercado no momento $t$ dado pela diferença entre a taxa de rentabilidade de mercado no momento t e a taxa de juro sem risco no ano $t$, em que foi utilizada a taxa de juro de uma obrigação de dívida pública alemã há 10 anos como referência. $0 \mathrm{p}$-value em parênteses testa se o alfa é significativamente diferente de zero. 0 p-value da diferença das carteiras testa a igualdade das rentabilidades entre uma dada carteira positiva e uma dada carteira negativa. As medidas de desempenho apresentadas dizem respeito a rentabilidades referidas ao período de um mês.

Tabela 8 Desempenho das novas carteiras na fase de subida de preços

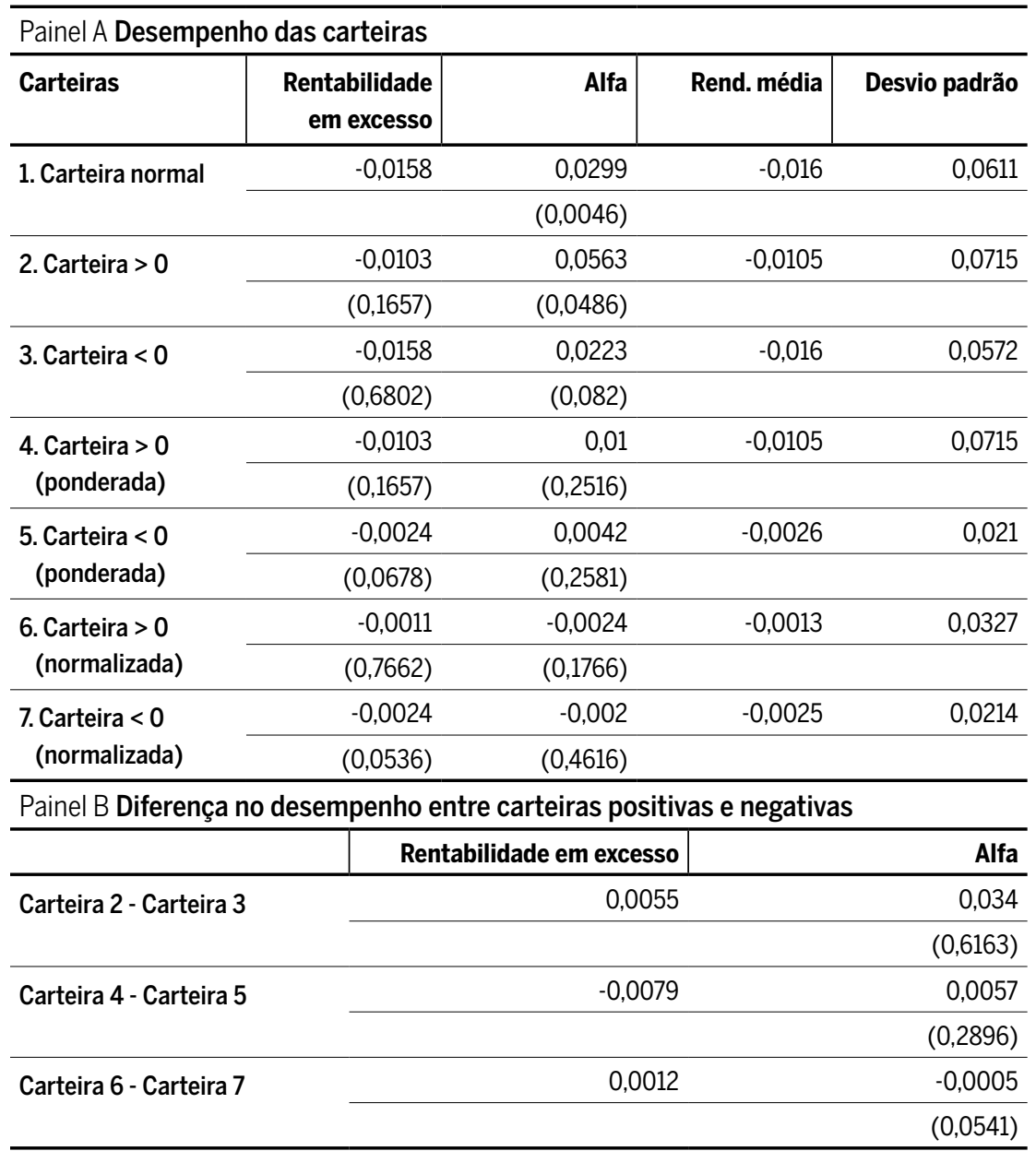

Fonte: Elaboração própria.

A fase de descida de preços foi definida como o período em que é negativa a média das rentabilidades do índice PSI20 nos 36 meses anteriores. Esse período vai desde outubro de 2008 a dezembro de 2011. Em todos os meses, durante tal período, os fundos de investimento são distribuídos por carteiras po- 
sitivas e por carteiras negativas com base no sinal da subscrição líquida verificada no mês anterior. $A$ rentabilidade em excesso é obtida pela diferença entre $R_{p t}$ e $R_{m t}$, onde $R_{p t}$ é a rentabilidade da carteira $i$ entre o mês $t$ - 1 e o mês $t$, e $R_{m t}$ é a rentabilidade do mercado de ações português, representada pela rentabilidade mensal do PSI20. O p-value em parênteses testa a diferença entre a rentabilidade de uma dada carteira e a rentabilidade de mercado. 0 valor de alfa é obtido pela regressão de um modelo unifatorial $R_{p t}-R_{f t}=\alpha_{p}+\beta_{p}\left(R_{m t}-R_{f t}\right)+\varepsilon_{p t}$, onde $R_{p t}-R_{f t}$ representa a rentabilidade em excesso da carteira de fundos p relativamente à taxa de juro sem risco no mês $t ; R_{m t}-R_{f t}$ representa o prêmio da carteira de mercado no momento $t$ dado pela diferença entre a taxa de rentabilidade de mercado no momento te a taxa de juro sem risco no ano $t$, em que foi utilizada a taxa de juro de uma obrigação de dívida pública alemã há 10 anos como referência. 0 p-value em parênteses testa se o alfa é significativamente diferente de zero. $0 \mathrm{p}$-value da diferença das carteiras testa a igualdade das rentabilidades entre uma dada carteira positiva e uma dada carteira negativa. As medidas de desempenho apresentadas referem-se a rentabilidades referidas ao período de um mês.

Os testes ao smart money nas duas fases de mercado sugerem que o contexto em que as decisões de investimento são tomadas tem relevância. $O$ gestor típico de fundos de investimento registra melhor (pior) desempenho do que o mercado na fase de subida (descida) dos preços. O desempenho dos investidores em fundos é também diferente. Na fase de tendência altista dos preços, os investidores parecem ser capazes de selecionar os melhores fundos a investir, mas não de desinvestir dos piores fundos. $\mathrm{Na}$ fase de tendência de descida de preços, o padrão inverte-se: parecem ser capazes de escolher os fundos a liquidar, mas não de escolher os fundos onde investir. A conjugação desses efeitos dilui o smart money verificado quando se considera a totalidade da amostra. Os alfas das diferenças entre as carteiras 2 e 3 e entre as carteiras 4 e 5 são superiores na fase de descida de preços, embora os valores obtidos não sejam estatisticamente significativos para níveis convencionais de significância.

\subsection{Teste de causalidade de Granger}

Os resultados descritos fornecem indicações acerca da relação entre as entradas de capital nos fundos e os alfas. Mas um alfa significativo apenas confirma a existência de uma correlação entre as variáveis sem nada indicar sobre o sentido da causalidade. Assim, é útil complementar a análise com o teste de causalidade de Granger. Ao permitir averiguar o sentido das relações estatísticas de causa e efeito entre subscrições líquidas e rentabilidades, esse teste proporciona visão mais completa da relação entre as decisões dos investidores e o desempenho dos fundos. Para além disso, permite perceber 
qual a duração da relação de causa e efeito. Uma vez que, da literatura se depreende que o comportamento dos investidores pode ser diferente consoante à dimensão dos fundos em que investem (Zheng, 1999; Yu, 2012), introduzimos a dimensão dos fundos no teste de causalidade de Granger por meio da divisão dos fundos em quartis de acordo com esse critério.

$\mathrm{Na}$ Tabela 9 apresentam-se os resultados do teste de causalidade a respeito da relação entre as rentabilidades médias mensais no mês anterior (RENDP) e as subscrições líquidas mensais, e sobre a relação entre as subscrições líquidas mensais e as rentabilidades médias mensais no mês seguinte (RENDF). Utilizamos tanto as subscrições líquidas em termos absolutos (SUB) como as subscrições líquidas normalizadas (SUBN) como medida dos fluxos financeiros. Como se referiu acima, a amostra é dividida em quartis conforme a dimensão dos fundos: o quartil 1 (4) representa os fundos que têm um montante sob gestão mais baixo (mais elevado). Ademais, se existir relação entre o desempenho dos fundos e movimentos de entrada/saída de capitais, é de interesse averiguar qual a duração dessa relação. Assim, em consonância com Bu e Lacey (2008), consideramos um desfasamento de até 12 meses.

Tabela 9 Teste de causalidade de Granger

Com 1 desfasamento

\begin{tabular}{|c|c|c|c|c|c|}
\hline Hipótese nula & Obs. & Quartil 1 & Quartil 2 & Quartil 3 & Quartil 4 \\
\hline RENDP não causa SUB & \multirow[t]{4}{*}{107} & 0,1314 & 0,1673 & 0,4748 & 0,1132 \\
\hline SUB não causa RENDF & & 0,7978 & 0,4615 & 0,2082 & 0,8112 \\
\hline RENDP não causa SUBN & & $* * 0,0074$ & 0,24 & 0,2347 & ${ }^{*} 0,0632$ \\
\hline SUBN não causa RENDF & & 0,789 & 0,6229 & $* 0,0617$ & 0,6437 \\
\hline
\end{tabular}

Com 2 desfasamentos

\begin{tabular}{|c|c|c|c|c|c|}
\hline Hipótese nula & Obs. & Quartil 1 & Quartil 2 & Quartil 3 & Quartil 4 \\
\hline RENDP não causa SUB & \multirow[t]{4}{*}{106} & 0,287 & 0,3076 & 0,1729 & $* * 0,0287$ \\
\hline SUB não causa RENDF & & 0,7407 & 0,6564 & 0,4492 & 0,9313 \\
\hline RENDP não causa SUBN & & $* * 0,0243$ & 0,4188 & $* * 0,0336$ & $* * 0,0441$ \\
\hline SUBN não causa RENDF & & 0,2882 & 0,8743 & 0,1841 & 0,6849 \\
\hline
\end{tabular}

Com 3 desfasamentos

\begin{tabular}{|c|c|c|c|c|c|}
\hline Hipótese nula & Obs. & Quartil 1 & Quartil 2 & Quartil 3 & Quartil 4 \\
\hline RENDP não causa SUB & \multirow[t]{4}{*}{105} & 0,3951 & 0,5349 & 0,3308 & ${ }^{*} 0,0606$ \\
\hline SUB não causa RENDF & & 0,8728 & 0,5624 & ${ }^{*} 0,0853$ & 0,9044 \\
\hline RENDP não causa SUBN & & $*^{* *} 0,0483$ & 0,5635 & $* * 0,0359$ & 0,1143 \\
\hline SUBN não causa RENDF & & 0,7227 & 0,9623 & ${ }^{*} 0,0726$ & 0,8997 \\
\hline
\end{tabular}


Com 4 desfasamentos

\begin{tabular}{|c|c|c|c|c|c|}
\hline Hipótese nula & Obs. & Quartil 1 & Quartil 2 & Quartil 3 & Quartil 4 \\
\hline RENDP não causa SUB & \multirow[t]{4}{*}{104} & 0,5733 & 0,4853 & 0,4045 & 0,1862 \\
\hline SUB não causa RENDF & & 0,8574 & 0,3254 & 0,1846 & 0,3605 \\
\hline RENDP não causa SUBN & & 0,14 & 0,6976 & $* * 0,0207$ & 0,2582 \\
\hline SUBN não causa RENDF & & 0,8585 & 0,9632 & 0,1459 & 0,4875 \\
\hline
\end{tabular}

Com 5 desfasamentos

\begin{tabular}{|c|c|c|c|c|c|}
\hline Hipótese nula & Obs. & Quartil 1 & Quartil 2 & Quartil 3 & Quartil 4 \\
\hline RENDP não causa SUB & \multirow[t]{4}{*}{103} & 0,4572 & 0,5717 & 0,4424 & 0,3168 \\
\hline SUB não causa RENDF & & 0,5821 & 0,3415 & 0,1942 & 0,1627 \\
\hline RENDP não causa SUBN & & 0,1342 & 0,776 & ${ }^{* *} 0,0439$ & 0,3384 \\
\hline SUBN não causa RENDF & & 0,4 & 0,976 & 0,1883 & 0,4064 \\
\hline
\end{tabular}

Com 6 desfasamentos

\begin{tabular}{|c|c|c|c|c|c|}
\hline Hipótese nula & Obs. & Quartil 1 & Quartil 2 & Quartil 3 & Quartil 4 \\
\hline RENDP não causa SUB & \multirow[t]{4}{*}{102} & 0,4608 & 0,6921 & 0,2864 & 0,6418 \\
\hline SUB não causa RENDF & & 0,4361 & 0,3055 & ${ }^{* *} 0,0287$ & $* 0,0759$ \\
\hline RENDP não causa SUBN & & 0,1241 & 0,8102 & **0,0131 & 0,5438 \\
\hline SUBN não causa RENDF & & 0,3365 & 0,9774 & 0,1975 & 0,275 \\
\hline
\end{tabular}

Com 7 desfasamentos

\begin{tabular}{|c|c|c|c|c|c|}
\hline Hipótese nula & Obs. & Quartil 1 & Quartil 2 & Quartil 3 & Quartil 4 \\
\hline RENDP não causa SUB & \multirow[t]{4}{*}{101} & 0,5553 & 0,7971 & 0,2823 & 0,5858 \\
\hline SUB não causa RENDF & & 0,2237 & 0,4218 & $* * 0,0446$ & *0,0754 \\
\hline RENDP não causa SUBN & & 0,175 & 0,6463 & $* * 0,0211$ & 0,4151 \\
\hline SUBN não causa RENDF & & 0,183 & 0,9288 & 0,3033 & 0,1695 \\
\hline
\end{tabular}

Com 8 desfasamentos

\begin{tabular}{|c|c|c|c|c|c|}
\hline Hipótese nula & Obs. & Quartil 1 & Quartil 2 & Quartil 3 & Quartil 4 \\
\hline RENDP não causa SUB & \multirow[t]{4}{*}{100} & 0,6995 & 0,7007 & 0,2802 & 0,7076 \\
\hline SUB não causa RENDF & & 0,3005 & 0,5112 & $* * 0,0413$ & ${ }^{*} 0,0506$ \\
\hline RENDP não causa SUBN & & 0,2604 & 0,6312 & $* * 0,029$ & 0,5969 \\
\hline SUBN não causa RENDF & & 0,2099 & 0,9473 & 0,2897 & 0,1219 \\
\hline
\end{tabular}

Com 9 desfasamentos

\begin{tabular}{|c|c|c|c|c|c|}
\hline Hipótese nula & Obs. & Quartil 1 & Quartil 2 & Quartil 3 & Quartil 4 \\
\hline RENDP não causa SUB & \multirow[t]{4}{*}{99} & 0,8205 & 0,7249 & 0,3718 & 0,8271 \\
\hline SUB não causa RENDF & & 0,3113 & 0,5058 & $* * 0,0035$ & ${ }^{*} 0,0605$ \\
\hline RENDP não causa SUBN & & 0,3635 & 0,7676 & ${ }^{*} 0,0542$ & 0,777 \\
\hline SUBN não causa RENDF & & 0,2779 & 0,9253 & ${ }^{* *} 0,0143$ & 0,1603 \\
\hline
\end{tabular}


Com 10 desfasamentos

\begin{tabular}{|c|c|c|c|c|c|}
\hline Hipótese nula & Obs. & Quartil 1 & Quartil 2 & Quartil 3 & Quartil 4 \\
\hline RENDP não causa SUB & \multirow[t]{4}{*}{98} & 0,8548 & 0,6134 & 0,4801 & 0,8876 \\
\hline SUB não causa RENDF & & 0,3598 & 0,5234 & $* * 0,0005$ & ${ }^{* *} 0,0099$ \\
\hline RENDP não causa SUBN & & 0,5236 & 0,8339 & ${ }^{*} 0,0521$ & 0,8303 \\
\hline SUBN não causa RENDF & & 0,3401 & 0,9517 & $* * 0,0045$ & ${ }^{*} 0,0527$ \\
\hline
\end{tabular}

Com 11 desfasamentos

\begin{tabular}{|c|c|c|c|c|c|}
\hline Hipótese nula & Obs. & Quartil 1 & Quartil 2 & Quartil 3 & Quartil 4 \\
\hline RENDP não causa SUB & \multirow[t]{4}{*}{97} & 0,8758 & 0,6824 & 0,4365 & 0,9349 \\
\hline SUB não causa RENDF & & 0,4697 & 0,5558 & $* * 0,0012$ & ${ }^{* *} 0,0194$ \\
\hline RENDP não causa SUBN & & 0,6945 & 0,8996 & $* * 0,0416$ & 0,8731 \\
\hline SUBN não causa RENDF & & 0,4311 & 0,9765 & $* * 0,0067$ & ${ }^{*} 0,0704$ \\
\hline
\end{tabular}

Com 12 desfasamentos

\begin{tabular}{|c|c|c|c|c|c|}
\hline Hipótese nula & Obs. & Quartil 1 & Quartil 2 & Quartil 3 & Quartil 4 \\
\hline RENDP não causa SUB & \multirow[t]{4}{*}{96} & 0,8474 & 0,4652 & 0,481 & 0,9567 \\
\hline SUB não causa RENDF & & 0,5838 & 0,1908 & $* * 0,0006$ & $* * 0,0040$ \\
\hline RENDP não causa SUBN & & 0,4295 & 0,7934 & $* 0,0543$ & 0,9114 \\
\hline SUBN não causa RENDF & & 0,479 & 0,9894 & $* * 0,0055$ & ${ }^{* *} 0,0261$ \\
\hline
\end{tabular}

Fonte: Elaboração própria.

$\left.{ }^{*}\right)$ : significativo ao nível de $10 \%$ de significância; $\left(^{* *}\right)$ : significativo ao nível de 5\% de significância.

Todos os meses, desde janeiro de 2003 a dezembro de 2011, a amostra de fundos de ações portuguesas é agrupada em quartis de acordo com o volume sob gestão. 0 quartil 1 (4) representa os fundos que possuem maior (menor) volume sob gestão. Para estudar a relação entre os montantes investidos nos fundos e o seu desempenho, é aplicado o teste de causalidade de Granger com desfasamentos de um a 12 meses. São usadas duas medidas relativas aos fluxos de investimento nos fundos: as subscrições líquidas em valor absoluto (SUB) e as subscrições líquidas normalizadas (SUBN), sendo que estas são o resultado da divisão da subscrição líquida do mês pelo volume sob gestão no final do mês anterior. RENDP representa a rentabilidade do fundo no mês $t-1$ e RENDF representa a rentabilidade do fundo no mês $t+1$ (RENDF).

Os resultados da Tabela 9 sugerem a existência do smart money nos fundos de maior dimensão ( $3^{\circ}$. e $4^{\circ}$. quartis), especialmente a partir do sexto desfasamento mensal.

Relativamente ao $3^{\circ}$. quartil e, em particular, quando são usadas as subscrições líquidas absolutas, existe relação de causa e efeito estatisticamente significativa entre subscrições e rentabilidades futuras a partir do $6^{\circ}$. desfasamento. Quando são testadas as subscrições normalizadas, tal relação só se torna estatisticamente relevante a partir do $9^{\circ}$. desfasamento. Nos períodos anteriores (exceto o $1^{\circ}$.), os resultados mostram existir 
relação de precedência estatística das rentabilidades passadas em face das subscrições. Tal aponta, portanto, para a existência do efeito momentum, ou seja, para a preferência por fundos que obtiveram bons resultados no passado recente. A sensibilidade ao desempenho recente dos fundos é consistente com os resultados obtidos em outros estudos (e.g., Gruber, 1996; Sapp; Tiwari, 2004).

Relativamente ao $4^{\circ}$. quartil, e se alargarmos o nível de significância para $10 \%$, também encontramos evidência a favor da existência do smart money. Mais uma vez, quando são testadas as subscrições absolutas, a relação entre subscrições e resultados futuros tem início no $6^{\circ}$. desfasamento, fortalecendo-se (significância a $5 \%$ ) do $10^{\circ}$. ao $12^{\circ}$. períodos. Quanto às subscrições normalizadas, existe relevância em termos estatísticos a partir do $10^{\circ}$. desfasamento, sendo significativo a um nível de $5 \%$ no último período.

Relativamente aos fundos de menor dimensão ( $1^{\circ}$. e $2^{\circ}$. quartis), não parece ocorrer nenhum tipo de relação entre subscrições e rentabilidades à exceção do efeito momentum para os fundos de mais reduzida dimensão ( $1^{\circ}$. quartil). Neste caso, os resultados mostram que os investidores são sensíveis aos resultados dos últimos três meses: dá-se um aumento (diminuição) de subscrições normalizadas na sequência de rentabilidades mais elevadas (mais baixas). Esse resultado é consistente com o obtido por Zheng (1999), por exemplo.

\section{Conclusões}

Este artigo insere-se na literatura acerca da capacidade dos investidores. $\bigcirc$ smart money, assim batizado por Zheng (1999), diz respeito à capacidade dos investidores para antecipar a rentabilidade dos fundos selecionando aqueles que subsequentemente vão apresentar o melhor desempenho.

O estudo centra-se no comportamento dos investidores em fundos do mercado português entre 2003 e 2011. São utilizados, pela primeira vez para esse mercado, três tipologias de teste do smart money a dados com frequência mensal. Também pela primeira vez é analisado o fenômeno em diferentes fases de mercado.

Entendidos no seu conjunto, os resultados indicam que o smart money se verificou. Os investidores, em geral, foram capazes de antecipar a evolução dos valores das rentabilidades dos fundos. Para além desse resultado 
principal, os testes permitiram revelar outras características do smart money. Em primeiro lugar, o efeito parece variar de forma significativa com a categoria dos fundos. Embora existam noutras categorias de fundos (ver Tabela 5), os resultados mostram que o smart money foi particularmente notório nos fundos em ações. Em segundo lugar, a capacidade de seleção de fundos de ações portuguesas varia com a fase do mercado de ações. Quando o mercado está em fase de subida (descida), os investidores têm a capacidade de selecionar os fundos onde investir (desinvestir), mas não evidenciam a capacidade de escolher os fundos a liquidar (comprar). Em terceiro lugar, os resultados indicam que o smart money se verificou sobretudo nos fundos de ações de maior dimensão, a partir de um horizonte temporal de 6 meses.

Tais resultados parecem contrariar os obtidos por Alves e Mendes (2011). É necessário ter em atenção, no entanto, que os resultados dos dois artigos não são diretamente comparáveis. Em primeiro lugar, os períodos temporais analisados são distintos. Alves e Mendes (2011) consideram o período 1993-2009, ao passo que o nosso artigo se concentra no período 2003-2011. Em segundo lugar, as diferenças podem ficar a dever-se à frequência dos dados usada. No caso das tabelas de contingência de Alves e Mendes (2011), foram empregados dados com frequência trimestral que podem tornar mais difícil a detecção do smart money. Em terceiro lugar, as técnicas de teste são também diferentes. Alves e Mendes (2011) usam tabelas de contingência e a análise multivariada, enquanto, no presente artigo, foram usados o teste de igualdade das rentabilidades médias, o teste de avaliação de desempenho e o teste de causalidade de Granger. Além disso, na análise multivariada de Alves e Mendes (2011), a inclusão de variáveis de controle relativas às características dos fundos e à fase de evolução do mercado de fundos pode contribuir para atenuar a relação estatística entre a variação das aplicações líquidas afetas a cada fundo e o seu desempenho subsequente.

O fato de se ter observado o smart money tem implicações importantes. Permite compreender, por exemplo, o que leva os indivíduos a investir em fundos que apresentam, em geral, desempenho inferior às de uma estratégia passiva. Por outro lado, a existência desse efeito lança dúvidas sobre a necessidade de se tomarem medidas de regulação para proteger a generalidade dos investidores das consequências das suas decisões financeiras.

É importante salientar ainda algumas limitações do estudo. Por um lado, a consideração de que existiu smart money no período analisado não deve 
ser confundida com a ideia de que os investidores são capazes de, a cada momento, selecionar de maneira bem-sucedida as alternativas de investimento que se lhes oferecem. $O$ universo de alternativas de investimento ao dispor dos investidores é muito vasto, e o resultado aqui obtido cinge-se apenas a uma parte desse universo, o dos fundos de investimento. Por outro lado, o fato de os métodos de avaliação de desempenho adotados exigirem a construção de carteiras homogêneas obrigou à consideração de uma subamostra de dimensão substancialmente mais reduzida do que a amostra inicial utilizada no teste de igualdade das médias (322 fundos contra 7 fundos). Por isso, ao contrário deste último teste, os resultados do modelo unifatorial e do teste de causalidade de Granger respeitam apenas um segmento do mercado de fundos de investimento.

No presente estudo, o objetivo principal foi a de testar a existência do smart money em Portugal. Seria interessante, como investigação futura, procurar entender se a capacidade de seleção dos investidores em fundos é influenciada pelo estilo de investimento (estratégias de momentum, estratégias de valor, etc.) adotado pelos gestores dos fundos e pelas características dos próprios fundos (dimensão, desempenho histórico, etc.).

\section{Referências}

ANDREU, L.; ORTIZ, C.; SARTO, J. L.; VICENTE, L. The smart money effect in two major mutual fund European industries. Working Paper, 2010.

ALVES, C.; MENDES, V. Does performance explain fund flows in small markets? The case of Portugal. Portuguese Economic Journal, v. 10, p. 129-47, 2011.

BERGGRUN, L.; LIZARZABURU, E. Fund flows and performance in Brazil. Journal of Business Research, v. 68, p. 199-207, 2015.

BU, Q.; LACEY, N. Do mutual funds exhibit a smart money effect? Quarterly Journal of Finance and Accounting, v. 47, p. 53-68, 2008.

COOPER, M. J.; GUTIERREZ, Jr., R. C.; HAMEED, A. Market states and momentum. Journal of Finance, v. 59, p. 1345-1365, 2004.

COSTA, L. T. L.; EID JR., W. O efeito smart money na indústria brasileira de fundos de ações. Working Paper. XXX Encontro da ANPAD, 2006.

DEL GUERCIO, D.; REUTER, J. Mutual fund performance and the incentive to generate alpha. Journal of Finance, v. 69, p. 1673-704, 2014.

FAMA, E. F.; FRENCH, K. R. Luck versus skill in the cross-section of mutual fund returns. Journal of Finance, v. 65, p. 1915-1947, 2010. 
FENG, X.; ZHOU, M.; CHAN, K. C. Smart money or dumb money? A study on the selection ability of mutual fund investors in China. The North American Journal of Economics and Finance, v. 30, p. 154-170, 2014.

FERREIRA, M. A; KESWANI, A.; MIGUEL, A. F.; RAMOS, S. B. The flow-performance relationship around the world. Journal of Banking \& Finance, v. 36, p. 1759-1780, 2012.

FRAZZINI, A.; LAMONT, O. A. Dumb money: Mutual fund flows and the cross-section of stock returns. Journal of Financial Economics, v. 88, p. 299-322, 2008.

FRENCH, K. R. The cost of active investing, Journal of Finance, v. 63, p. 1537-1573, 2008.

FRIEDSEN, G. C.; SAPP, T. Mutual fund flows and investor returns: An empirical examination of fund investor timing ability. Journal of Banking \& Finance, v. 31, p. 2796-2816, 2007.

GARCÍA, D. Sentiment during recessions. Journal of Finance, v. 68, p. 1267-1300, 2013.

GHARGHORI, P.; SUJOTO, C.; VEERARAGHAVAN, M. How smart is money? An investigation into investor behaviour in the Australian managed fund industry. Pacific-Basin Finance Journal, v. 15, p. 494-513, 2007.

GHARGHORI, P.; SUJOTO, C.; VEERARAGHAVAN, M. Are Australian investors smart? Australian Journal of Management, v. 32, p. 525-44, 2008.

GRUBER, M. J. Another puzzle: The growth in actively managed mutual funds. Journal of Finance, v. 51, p. 783-810, 1996.

HAQ, I.; KURSHED, A.; ESPENLAUB, S. Where did the smart money go? Working Paper, University of Manchester, 2011.

KESWANI, A.; STOLIN, D. Which money is smart? Mutual fund buys and sells of individual and institutional investors. Journal of Finance, v. 63, p. 85-116, 2008.

MARZUKI, A.; WORTHINGTON, A. C. The smart money effect in Malaysian equity funds: Islamic versus conventional. Working Paper, 2011.

PENG, C. L.; CHEN, M. L.; SHYU, S. D.; WEI, A. P. When is money likely to be smart? Evidence from mutual fund investors in Taiwan. Investment Analysts Journal, v. 73, p. 13-25, 2011.

RENNEBOOG, L.; TER HORST, J.R.; ZHANG, C. The price of ethics and stakeholder governance: The performance of socially responsible mutual funds. Journal of Corporate Finance, v. 14, p. 302-322, 2008.

SAPP, T.; TIWARI, A. Does stock return momentum explain the smart money effect? Journal of Finance, v. 59, p. 2605-2622, 2004.

VARGA, G. Mutual fund flow and past information: Is the Brazilian investor smart? Working Paper. XXXV Encontro da ANPAD, 2011.

VICENTE, L.; ORTIZ, C.; ANDREU, L. Is the average investor smarter than the average euro? Journal of Financial Services Research, v. 40, p. 143-161, 2011.

YU, H. Where are the smart investors? New evidence of the smart money effect. Journal of Empirical Finance, v. 19, p. 51-64, 2012.

ZHENG, L. Is money smart? A study of mutual fund investors fund selection ability. Journal of Finance, v. 54, p. 901-33, 1999. 


\section{Sobre os autores}

JúlioLobão-jlobao@fep.up.pt

Faculdade de Economia da Universidade do Porto, Porto, Portugal.

Miguel Oliveira-10417019@fep.up.pt

Faculdade de Economia da Universidade do Porto, Porto, Portugal.

\section{Sobre o artigo}

Recebido em 10 de maio de 2015. Aprovado em 20 de novembro de 2015. 